\title{
Speciation of heavy metals in environmental water by ion chromatography coupled to ICP-MS
}

Received: 29 May 2001 / Revised: 30 July 2001 / Accepted: 25 August 2001 / Published online: 20 December 2001

(C) Springer-Verlag 2001

\begin{abstract}
Biogenic (e.g. phytochelatins, porphyrins, DOM) as well as anthropogenic (e.g. NTA, EDTA, phosphonates) chelators affect the mobility and cycling of heavy metals in environmental waters. Since such chelators can form strongly bound anionic heavy metal complexes that are stable and highly mobile, anion-exchange chromatography coupled to ICP-MS was investigated. A narrow bore HPLC system was connected to a micro concentric nebuliser for in-line sample introduction. A new chromatographic procedure based on a synthetic hydrophilic quaternary ammonium anion exchanger in combination with nitrate as a strong eluent anion, and gradient elution, provided high separation selectivity and a large analytical window. Low detection limits $\left(\mathrm{nmol} \mathrm{L}{ }^{-1}\right)$ were achieved by on-column matrix removal and sample preconcentration. This allowed the method to be successfully applied to different environmental research areas. In ecotoxicological studies of heavy metal effects on algae low concentrations of metal EDTA complexes were determined in nutrient solutions without interference from high (buffer) salt concentrations. In groundwater, infiltrated by a polluted river, mobile metal EDTA species were observed. In river water of different pollution levels beside CuEDTA other anionic $\mathrm{Cu}$-complexes were found in $n m o l \mathrm{~L}^{-1}$ concentrations.
\end{abstract}

Keywords Gradient anion-exchange chromatography • Metal chelates - Metal speciation - Environmental water

\section{Introduction}

From anthropogenic as well as from biological activities various complexing agents are released into the hydro-

A.A. Ammann (汭

Swiss Federal Institute for Environmental Science

and Technology (EAWAG),

Postfach 611, 8600 Dübendorf, Switzerland

e-mail: adrian.ammann@eawag.ch sphere [1] where they, together with geochemical ligands, constitute the metal complexation chemistry [2]. Heavy metal speciation of this kind of chelator is of particular interest since, at the same concentrations level as the metals, strong binding chelators fully dominate metal speciation. Among them, aminopolycarboxylates [1] were found, such as the persistent EDTA [3] and phosphonates [4]. The mobility and (eco)toxicological effects of heavy metals depend on the chemical properties of the metal species in surface interactions $[5,6]$ and exchange kinetics $[7,8]$ which cannot be calculated from total concentrations [9].

Most stable and mobile chelators and their heavy metals complexes are present in the environment in anionic form. This allows an ion-exchange procedure to be directly applied to analytes without derivatisation prior to analysis. Because of the stronger ion-interaction forces, an ion-exchange-based separation procedure can provide outstanding performance regarding matrix-compatibility, selectivity, and sensitivity with on column sample preconcentration. Comparing different liquid chromatographic methods it was concluded [10] that ion exchange is one of the most useful chromatographic techniques for speciation in environmental samples.

The potential of capillary electrophoresis (CE) was also evaluated. The separation of some metal EDTA and NTA complexes was reported $[11,12]$ that were detected by UV and laser-induced fluorescence [13].

Anion-exchange chromatography was also reported for separation of negatively charged metal complexes with carbonate eluents at $\mathrm{pH}>9$ detected by conductivity [14, $15]$ and UV-Vis [16, 17]. Suppression of this carbonate eluent improved the signal-to-noise ratio in ESI-MS detection [18] and allowed the determination of nano-molar concentrations. However carbonate elutes anionic metal complexes together with sample ions $\mathrm{NO}_{3}{ }^{-}$and $\mathrm{SO}_{4}{ }^{2-}$ at a $\mathrm{pH}$ where, e.g., $\mathrm{Al}, \mathrm{Fe}$, and $\mathrm{Zn}$ chelates are not stable. The $\mathrm{pH}$ cannot be adjusted below 9 without substantial loss in eluent strength that is proportional to the increase of the weak eluent anion $\mathrm{HCO}_{3}{ }^{-}$.

This work reports on the extended application of anion-exchange chromatography in metal speciation that 
covers the range of natural water $\mathrm{pH} 6-8$ and has broad selectivity to separate complexes of diverse chelators in the same run. Coupling to an ICP-MS was used for element identification and low detection limits were obtained for heavy metals [19].

\section{Experimental}

Chemicals and samples

Nitrilotriacetic acid (NTA), ethylenediaminetetraacetic acid disodium salt (EDTA), $N$-(2-hydroxyethyl)ethylenediaminetriacetic acid (HED3A), and citric acid were purchased from Fluka or Merck in the highest purity available. Ethylenediaminetriacetic acid (ED3A) and ethylenediaminedisuccinate (EDDS) was a kind gift from M. Bucheli-Witschel and T. Egli (EAWAG). Ethylenediaminetetramethylenephosphonic acid (EDTMP) was obtained as Dequest 2041 (Monsanto) from H. Felber (EMPA, St. Gallen).

Metal complexes stock solutions $\left(1 \mathrm{mmol} \mathrm{L}^{-1}\right)$ were prepared by adding equimolar ligand solutions to the diluted AAS-standard (J. T. Baker) solution followed by controlled neutralisation. After a few days at room temperature the solutions are ready to use. $\mathrm{Fe}$-chelates were stored in the dark. Dilutions from stocks were freshly prepared daily for concentrations $>0.1 \mu \mathrm{mol} \mathrm{L}{ }^{-1}$, or immediately before use for lower concentrations.

Calibration curves were obtained by the method of standard additions to the samples.

Samples were passed through prewashed filters $(0.45 \mu \mathrm{m})$ in the field and stored at $4{ }^{\circ} \mathrm{C}$ in the dark.

\section{Chromatography}

A totally PEEK system was used, consisting of a DX-500 (Dionex) microbore gradient pump, a Rheodyne (9126) injection valve ( $270 \mu \mathrm{L}$ loop) and a low capacity (0.011 mequiv.) microbore anion separator column (AS11, 250×2 mm, Dionex) with hydrophilic quaternary alkanol ammonium anion exchange sites. The eluent flow (440 $\mu \mathrm{L} \mathrm{min}{ }^{-1}$ ) was chosen as optimum for fast separation and highest nebuliser mass transfer. Eluents were prepared $\mathrm{CO}_{2-}$ free and kept under $\mathrm{He}$ over pressure. Eluent $\mathrm{pH}$ was adjusted with conc. $\mathrm{NH}_{4} \mathrm{OH}$. Gradients were mixed linearly ( $\left.0-8 \mathrm{~min}\right)$ from water and $200 \mathrm{mmol} \mathrm{L}^{-1} \mathrm{NH}_{4} \mathrm{NO}_{3}$ solution and the $\mathrm{pH}$ monitored several times a day at the pump head drain valve after mixing the sol- vent lines. Metals were removed on line from the eluents by passage through a column $(50 \times 4 \mathrm{~mm})$ filled with strong cation exchanger 50W-X8 (Bio-Rad). The stability and reproducibility of flow rate, evolving gradient, and nebulisation was observed on $\mathrm{m} / \mathrm{z}=30$. Sample preconcentration was achieved either by use of the sample loop or by injections of larger volumes $(1-5 \mathrm{~mL})$ on AG11 $(50 \times 4 \mathrm{~mm}$, Dionex) in the loop position. Method detection limits depended on several parameters - the sample volume preconcentrated, the actual metal background in the eluent as well as on the column and on the detected isotope sensitivity. However the dominating parameter was the sample volume that can be preconcentrated. It is limited by the combination of the capacity of the preconcentrator column and the content of sample anions $\left(\mathrm{Cl}^{-}\right.$, $\mathrm{NO}_{3}{ }^{-}, \mathrm{CO}_{3}{ }^{2-}, \mathrm{SO}_{4}{ }^{2-}$ ). Metal deposited on the column from lower stability complexes $(\log K<9)$ [20] and metal remobilisation was controlled as recommended by Hering [21] and Szpunar [22] for size-exclusion chromatography. Only free chelator was able to mobilise metal from the column but not chelator coordinated to a metal, e.g. EDTA mobilised metal but CaEDTA did not.

\section{Coupling and ICP-MS measurements}

The column was connected to a micro concentric nebuliser MCN-100 M2 (Cetac) mounted on Scott-type Ryton double pass spray chamber. The ICP-MS (Elan 5000, Perkin-Elmer-Sciex) sensitivity and ion optics were optimised by measuring a solution of $\mathrm{Li}, \mathrm{Rh}$, and $\mathrm{U}\left(10 \mu \mathrm{g} \mathrm{L}^{-1}\right)$ delivered by a peristaltic pump (Gilson) at the chromatography flow rate. Other ICP-MS operating conditions were as follows: RF power: $1100 \mathrm{~W}$, Ar gas flows $\left(\mathrm{L} \mathrm{min}^{-1}\right)$ : plasma (15), auxiliary: (1), nebuliser: (0.8-1.0).

For fast sequential detection dwell times $(25-100 \mathrm{~ms})$, the number of replicates and the number of detected $\mathrm{m} / \mathrm{z}$ values were selected according to the chromatogram time needed to elute components detected by at least 10 points/peak. Data were acquired in the Graphic mode. Single-mass chromatograms and peak integrals were obtained from Chromafile MSplus software (LabControl) Element isotopes were detected at the $\mathrm{m} / \mathrm{z}$ values of minimal interference (C: 12, Fe: 57, Co: 59, Ni: 60, Cu: 65, Zn: 66, Cd: 111 and $\mathrm{Pb}: 208)$ or, for higher sensitivity, more abundant isotopes were chosen $(\mathrm{Cu}: 63, \mathrm{Cd}: 114)$, if chromatography showed no coelution of species that contain interfering elements. During acquisition of high signals (e.g. $\mathrm{m} / \mathrm{z} 12$ or 30 ) the detector had to be desensitised (omni range 10-20) because detector overflow in one chromatogram caused a data cut off in all other chromatograms of the same run during data transfer with Chromfile.
Table 1 Species characteristics and measured retention times $\left(t_{R}\right)$ in isocratic elution

Species distribution (\%) was calculated by Vminteqa [33] for $\mathrm{pH} 7$ and $8\left(50 \mathrm{mmol} \mathrm{L}^{-1}\right.$ $\mathrm{NH}_{4} \mathrm{NO}_{3}$, free chelator $0.1 \mathrm{mmol} \mathrm{L}^{-1}$, metal species $1 \mu \mathrm{mol} \mathrm{L}-1) . \operatorname{LogK}(\mathrm{I}=0.1$, $25^{\circ} \mathrm{C}$ ) values taken from Ref. [24]

\begin{tabular}{|c|c|c|c|c|c|}
\hline \multirow[t]{2}{*}{ Ligand/Complex } & \multirow{2}{*}{$\begin{array}{l}\text { Species } \\
\text { charge }\end{array}$} & \multicolumn{2}{|c|}{ Distribution } & \multirow{2}{*}{$\begin{array}{l}\mathrm{t}_{\mathrm{R}}[\mathrm{min}] \\
\text { (eluent, } \\
\text { mmol L-1) }\end{array}$} & \multirow{2}{*}{$\begin{array}{l}\text { LogK- } \\
\text { range }\end{array}$} \\
\hline & & $\%(\mathrm{pH} 7)$ & $\%(\mathrm{pH} 8)$ & & \\
\hline NTAH & -2 & 99.9 & 98.6 & $4.0(20)$ & \\
\hline MeNTA Me(NTA $)_{2}$ & $-1 \ldots-4$ & $99-100$ & $89-100$ & $4.0-5.5(20)$ & $10-16$ \\
\hline HED3AH & -2 & & & $3.0(20)$ & \\
\hline MeHED3A & -1 & & & $2.0(20)$ & $13-20$ \\
\hline ED3AH & -2 & & & $3.0(20)$ & \\
\hline MeED3A & -1 & & & $2.0(20)$ & \\
\hline EDTAH & -3 & 93.4 & 99.3 & $3.5(50)$ & \\
\hline MeEDTA & -2 & $99-100$ & 100 & $2.0(50)$ & $15-25$ \\
\hline EDDSH & -3 & & & $3.0(50)$ & \\
\hline MeEDDS & -2 & & & $2.0(50)$ & $12-16$ \\
\hline Citr & -3 & 92.7 & 99.2 & $4.0(70)$ & \\
\hline MeCitr & -2 & & & - & $4-6$ \\
\hline EDTMP & -5.4 & & & $4.7(130)$ & \\
\hline MeEDTMP & $-5.0 \ldots-5.5$ & & & $3.5-4.0(130)$ & $15-23$ \\
\hline $\mathrm{NH}_{4}^{+}$ & & 99.5 & 95.6 & - & \\
\hline $\mathrm{NH}_{3}$ & & 0.5 & 4.4 & - & \\
\hline
\end{tabular}




\section{Results and discussion}

The hydrophilic column used exhibited a high affinity for chelating agents and its complexes. This afforded a strong eluent anion in high concentrations which should still be compatible with ion extraction from an ICP into a MS. Ammonium nitrate was an optimal eluent because it is thermally not stable (decomposing to gaseous components) and has a high affinity [23] to hydrophilic anion exchangers. Two superior properties of this eluent should be emphasised:

1. the $\mathrm{pH}$ can be adjusted from acidic to slightly basic without impairing the eluent strength, and

2. the high concentration tolerated by the plasma enabled the powerful gradient elution without additional space charge effects [20].

The chromatographic behaviour of the chelators and their metal complexes analysed (Table 1) represented several aspects of complexation chemistry as well as environmental concern. The anionic character of the species varied between -1 and -5.5 and the ligands represent a broad range of equilibrium stability constants [24] (see Table 1). The metals analysed play either a crucial role in metal speciation ( $\mathrm{Fe}, \mathrm{Zn}, \mathrm{Cu}[9])$ or represent metals reacting with different rate constants [25], e.g. $\mathrm{Ni}$ and $\mathrm{Pb}$ as slowly and fast reacting metals, repectively.

Table 1 gives an overview of isocratic eluent concentrations needed to elute uncomplexed chelators and their metal complexes within a reasonably short retention time and within a peak that can be integrated. As can be concluded from the broad range of isocratic concentrations the eluent provided high selectivity. The affinity of the column for free metals required a complex stability of $\log \mathrm{K}>10$ for metal complexes in order to survive the chromatographic conditions. According to an established anion-exchange separation mechanism [20] more highly charged species required higher eluent concentrations of about $32 \mathrm{mmol} \mathrm{L}^{-1} \mathrm{NO}_{3}^{-}$-/charge unit. So a particular isocratic eluent provided high selectivity but only a narrow separation window. Only one or maybe two chelators and their complexes can be separated in the same run. However in environmental waters several chelators including partially degraded compounds [1] (e.g. loss of a carboxylic group $[26,27,28]$ ) are more likely to occur. Therefore gradient elution was investigated and successfully separated, in the same run, the chelators and their complexes given in Table 1 [20]. Gradients were also used for chemical speciation in different environmental research areas as described below.

\section{Ecotoxicological investigations with algae}

In ecotoxicological studies of heavy metal effects on algae, buffered metals in nutrient solutions are used to maintain a constant metal supply [29]. This is achieved by metal complexation of sufficient stability. A nutrition me-

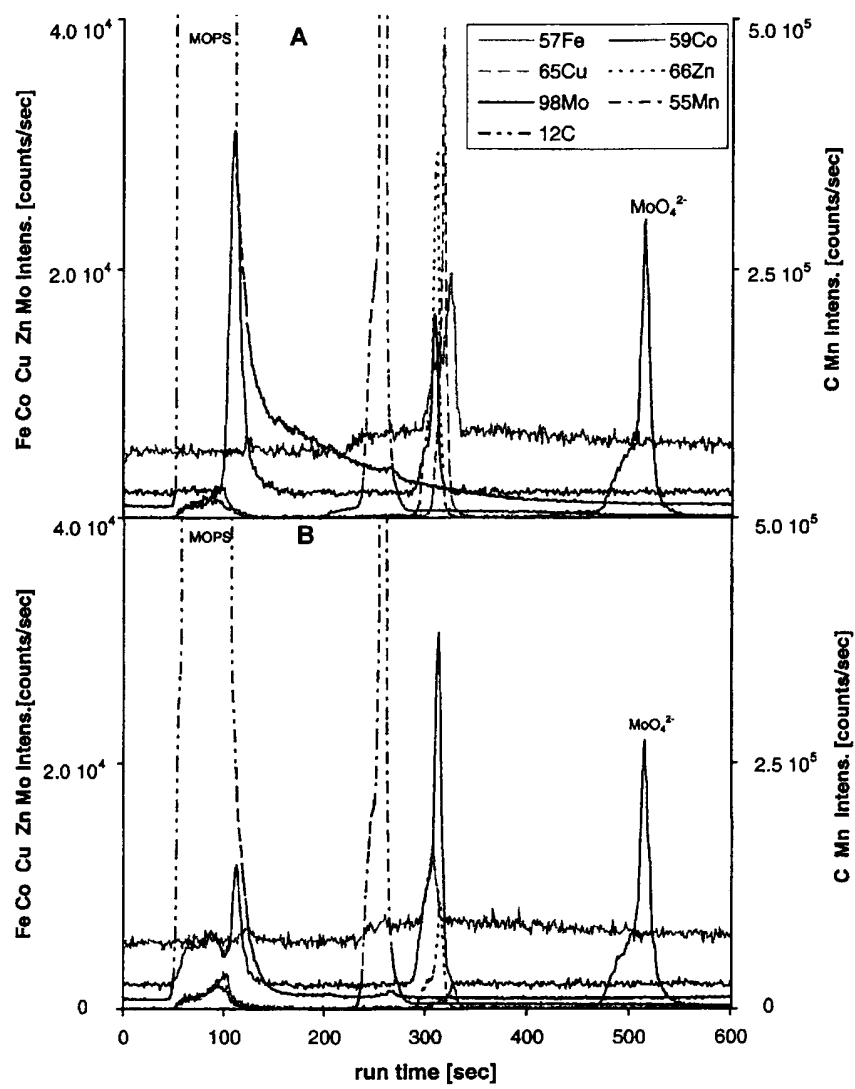

Fig. 1 Gradient (20-100 mmol $\left.\mathrm{L}^{-1}\right)$ anion-exchange chromatograms of algae nutrient media containing EDTA-buffered heavy metals. A. Stability of the MeEDTA complexes after 30 days at $4{ }^{\circ} \mathrm{C}$ in the dark. B. The same media filtered after incubation with algae at room temperature and with illumination

dia which used EDTA for metal stabilisation was analysed (see Fig. 1). It contained the metal-EDTA species at low concentrations (component $\left(\mu \mathrm{mol} \mathrm{L} \mathrm{L}^{-1}\right)$ : Co $(0.05), \mathrm{Cu}$ (0.1), $\mathrm{Mn}(1.0), \mathrm{Zn}(0.1), \mathrm{Fe}(0.9)), \mathrm{MoO}_{4}{ }^{2-}(0.08)$ and EDTA (20), beside high salt concentrations $\left(\mathrm{mmol} \mathrm{L}^{-1}\right)$, (morpholinopropanesulfonic acid (MOPS) (10), $\mathrm{CaCl}_{2}$ (0.5), $\mathrm{MgSO}_{4}$ (0.15), $\mathrm{NaHCO}_{3}$ (1.2), $\mathrm{KHPO}_{4}(0.05)$, $\mathrm{NaNO}_{3}(1.0)$ ). Molybdate cannot react with EDTA and remained stable during incubation with algae. It therefore could be used as an internal standard. The large amount of organic buffer salt MOPS was well separated (peak 12C in Fig. 1) and did not impair the separation and quantification of MeEDTA species. During storage of the medium the MeEDTA species remained stable. Cobalt clearly showed ligand exchange that was already present after mixing the medium, whereas after incubation with algae most $\mathrm{Cu}-$, Zn- and FeEDTA disappeared, as demonstrated in Fig. 1B. Without any sample pretreatment (except filtration) the large loop injection was sufficiently sensitive. The method was ideally suited to observation of a bunch of single anionic metal species and its interaction with algae. The dynamic and exact reaction path is under further investigation. 


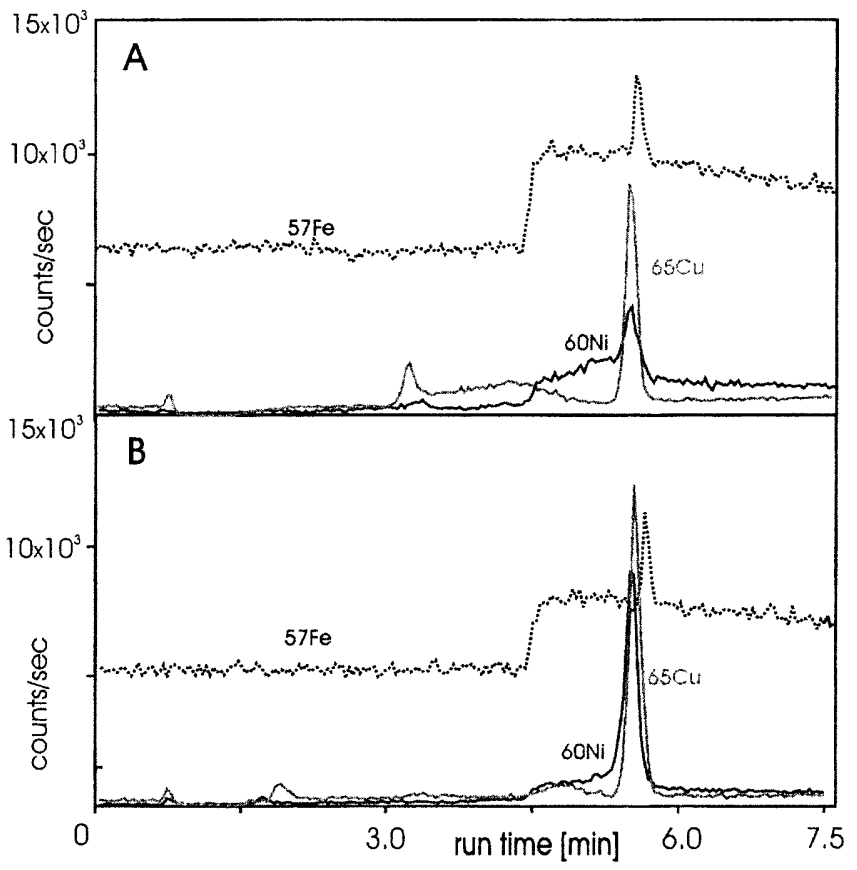

Fig. 2 Gradient (10-200 $\mathrm{mmol} \mathrm{L}^{-1}$ ) anion-exchange chromatograms of groundwater polluted by infiltrating river water. A. Metal EDTA complexes observed in a groundwater sample. B. The same groundwater after spiking with $\mathrm{Cu}$ - and NiEDTA $\left(10 \mathrm{nmol} \mathrm{L}^{-1}\right)$

Mobility of MeEDTA from river water into groundwater

Metal EDTA species could be observed at the well investigated site Glattfelden [30] where the polluted River Glatt [31] is infiltrating permanently $\left(\sim 0.5 \mathrm{~m}^{3}\right.$ day $\left.^{-1} \mathrm{~m}^{-2}\right)$ into the top groundwater layer. Samples were taken in the mixing zone ( $16 \mathrm{~m}$ from river bank and at $6 \mathrm{~m}$ depth). In the river water 30-90 nmol L-1 EDTA was usually determined [13]. Figure 2 depicts chromatograms from preconcentrated samples $(2 \mathrm{~mL})$ and shows metal EDTA species identified and quantified by standard addition (NiEDTA $6 \mathrm{nmol} \mathrm{L}^{-1}$, CuEDTA $16 \mathrm{nmol} \mathrm{L}^{-1}$, and FeEDTA $19 \mathrm{nmol} \mathrm{L}^{-1}$ ). This provided direct information on metal species that has previously been attempted by determination by EDTA-species calculation[9].

\section{$\mathrm{Cu}$ species in river water}

$\mathrm{Cu}$ species were determined in a river at four different locations that represent catchment areas with different pollution levels [32]. Due to low nanomolar concentrations, river water samples had to be preconcentrated $(5 \mathrm{~mL})$. Measuring both $\mathrm{Cu}$ isotopes $\left({ }^{63} \mathrm{Cu}\right.$ and ${ }^{65} \mathrm{Cu}$ ), the occurrence of $\mathrm{Cu}$ in the species was verified by the maintained ratio according to their natural abundance. The relative pollution level at the four sites was reflected by the dissolved copper concentration $\left([\mathrm{Cu}]_{\mathrm{d}}\right.$, Fig. 3) which was the upper limit for the sum of all $\mathrm{Cu}$ complexes. At the station Necker, after running through an almost unpopulated

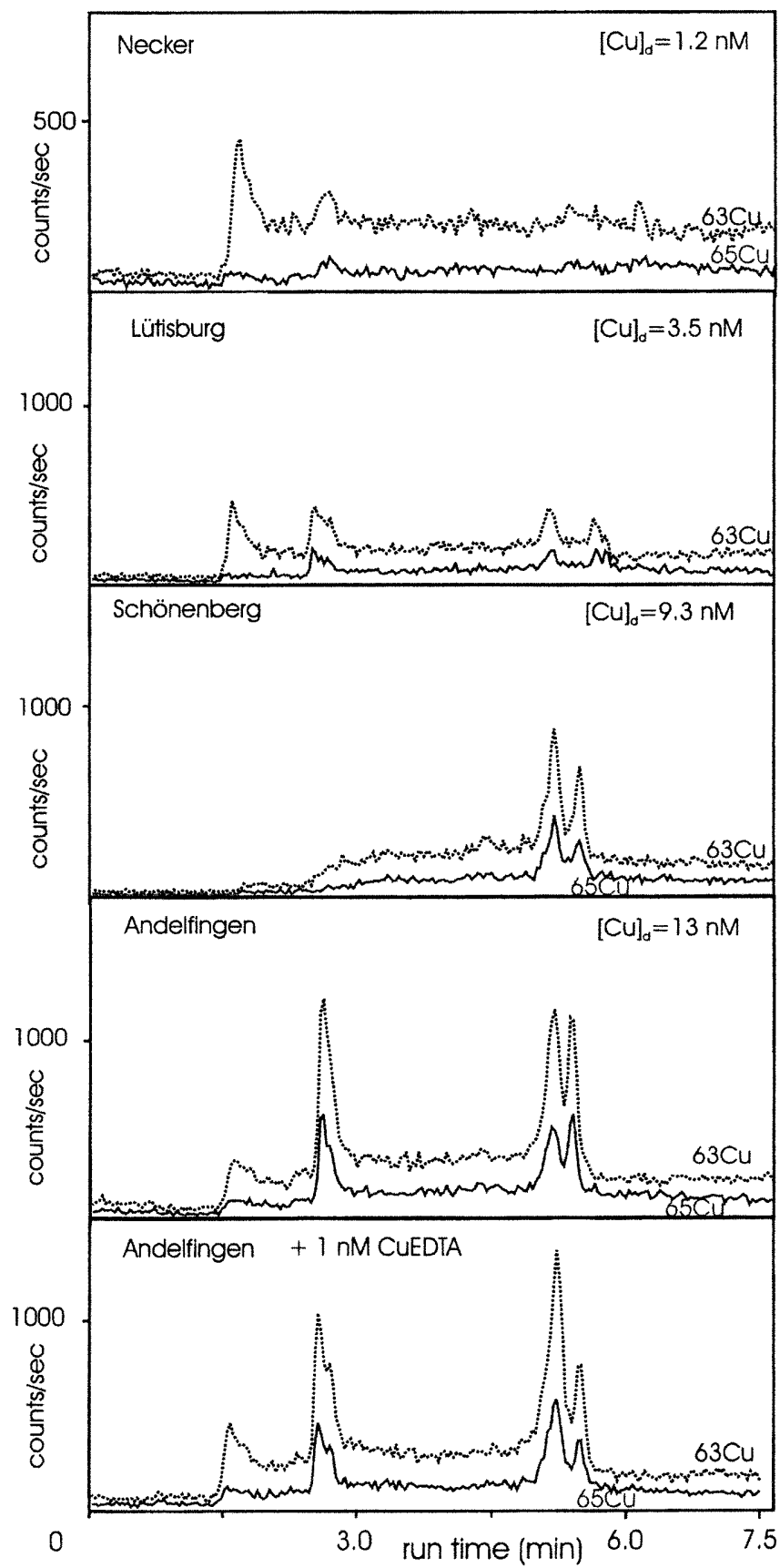

Fig. $3 \mathrm{Cu}$ species in the river Thur at sites representing different pollution levels indicated by increasing dissolved copper concentrations $\left([\mathrm{Cu}]_{\mathrm{d}}\right)[32]$. Filtered samples were used to determine $[\mathrm{Cu}]_{\mathrm{d}}$ by ICP-MS. Gradient $\left(20-200 \mathrm{mmol} \mathrm{L}^{-1}\right)$ elution separated three $\mathrm{Cu}$ species. At $t_{\mathrm{R}}=5.3 \mathrm{~min} \mathrm{CuEDTA}^{2-}$ was identified and quantified by standard addition to the sample from Andelfingen

alpine catchment area, no $\mathrm{Cu}$ species was detected. Further downstream increasing [CuEDTA $\left.{ }^{2-}\right]$ was detected at all other locations. At the station Andelfingen, after the contributions from industrial and agriculture areas, the highest $\left[\mathrm{CuEDTA}^{2-}\right]\left(=2 \mathrm{nmol} \mathrm{L}^{-1}\right)$ was determined; also present were other yet unidentified $\mathrm{Cu}$ complexes - one at $t_{R}=2.6$ min bearing approx. one charge unit less and an- 
other $\left(t_{R}=5.5 \mathrm{~min}\right)$ of about the same anionic charge as $\mathrm{CuEDTA}^{2-}$. Based on the quantification of $\mathrm{Cu}$ the three $\mathrm{Cu}$-species detected accounted together for $40 \%$ of $[\mathrm{Cu}]_{\mathrm{d}}$. This is in good agreement with investigations done by other methods at this site [32]. For example, size fractionation of trace metals by ultra filtration found $\mathrm{Cu}$-binding ligands in the fractions $<10 \mathrm{kD}$ and voltammetric measurements including ligand titration by $\mathrm{Cu}^{2+}$ observed an over all conditional stability constant of $\log \mathrm{K}=14.6$ for the Cu-binding ligands.

\section{Conclusions}

The use of on column preconcentration and matrix removal, a very efficient feature of anion exchange gradient separation, in combination with sensitive on line detection by ICP-MS, provided detection limits of around $10 \mathrm{nmol} \mathrm{L}{ }^{-1}$ for large-loop injection and $1 \mathrm{nmol} \mathrm{L}^{-1}$ for injection on a preconcentrator column. The eluent, which was highly compatible with the ICP, provided a large selectivity for the elution of several anionic metal species within a few minutes. The eluent $\mathrm{pH}$ can be adjusted in a broad range without compromising eluent strength. Based on all these features, the procedure presented is likely to become the method of choice for the search and behaviour of anionic metal complexes in different matrices and research areas. It can provide accurate concentrations of single strongly bound metal species, information that is complementary to voltammetric methods.

Acknowledgements Thanks are due to D. Kistler and R. Schönenberger for sampling the river and groundwater, to B. Wagner for preparation of the algae medium, and to D. Weirich and L. Sigg for helpful discussions.

\section{References}

1. Bucheli-Witschel M, Egli T (2001) FEMS Microbiol Rev 25: 69-106

2. Buffle J (1988) Complexation reactions in aquatic systems - an analytical approach. Ellis Horwood Series in Analytical Chemistry, New York

3. Kari FG, Giger W (1995) Environ Sci Technol 29:2814-2827

4. Nowack B (1998) Water Res 32:1271-1279

5. Nowack B, Sigg L (1996) J Colloid Interface Sci 177:105

6. Jardine PM, Taylor DL (1995) Geoderma 67:125-140
7. Xue H, Jansen S, Prasch A, Sigg L (2001) Environ Sci Technol 35:539

8. Xue H, Sigg L, Kari FG (1995) Environ Sci Technol 28:59-68

9. Nowak B, Xue H, Sigg L (1997) Environ Sci Technol 31:866872

10. Blanco-González E, Sanz-Medel A (2000) Liquid chromatographic techniques for trace element speciation analysis. In: Caruso JA, Sutton KL, Ackley KL (eds) Element speciation new approaches for trace elemental analysis. Comprehensive analytical chemistry, vol 33. Elsevier, Amsterdam, chap 4

11. Owens G, Ferguson VK, McLaughlin MJ, Singletone I, Reid RJ, Smith FA (2000) Environ Sci Technol 34:885-981

12. Bürgisser CS, Stone AT (1997) Environ Sci Technol 31:26562664

13. Ye L, Wong JE, Lucy CA (1997) Anal Chem 69:1837-1843

14. Tanaka T (1985) Fresenius Z Anal Chem 320:125-127

15. Hajós P, Révész G, Horváth O, Peear J, Sarzanini C (1996) J Chromatogr Sci 34:291-299

16. Schwedt G, Kondratjonok B (1989) Fresenius Z Anal Chem 332:855-861

17. Taylor DL, Jardine PM (1995) J Environ Qual 24:789-792

18. Bauer KH, Kepper TP, Maes A, Schatz V, Voihsel MJ (1999) J Chromatogr A 837:117-128

19. Ackley KL, Sutton KL, Caruso JA (2000) The use of ICP-MS as a detector for elemental speciation studies. In: Caruso JA, Sutton KL, Ackley KL (eds) Element speciation - new approaches for trace elemental analysis. Comprehensive analytical chemistry, vol 33. Elsevier, Amsterdam, Chap 9

20. Ammann AA (2001) submitted to J Chromatogr A

21. Piatina TB, Hering JG (2000) J Environ Qual 29:1839-1845

22. Vacchina V, Polec K, Szpunar J (1999) J Anal At Spectrom 14: 1557-1566

23. Fritz JS, Gjerde DT (2000) Ion chromatography, 3rd edn. Wiley-VCH, Weinheim, p 48

24. Martell AE, Smith RM (1989) Critical stability constants. Plenum Press, New York

25. Morel FMM, Hering JG (1993) Principles and application of aquatic chemistry. Wiley and Sons, New York, chap 6

26. Ternes TA, Stumpf M, Steinbrecher T, Brenner-Weiss G, Haberer K (1996) Vom Wasser 87:275-290

27. Karametaxas G, Hug SJ, Sulzberger B (1995) Environ Sci Technol. 29:2992-3000

28. Lockhart HB, Blakeley RV (1975) Environ Sci Technol 9: $1035-1038$

29. Price NM, Harrison GI, Hering JG, Hudson RJM, Nirel PMV, Palenik B, Morel FMM (1988/89) Biol Oceanogr 6:443-461

30. Hoehn E, Santschi PH (1987) Water Resour Res 25:1795-1803

31. Von Gunten HR, Karametaxas G, Krähenbühl U, Kulsys M, Giovanoli R, Hoehn E, Keil R (1991) Geochim Cosmochim Acta 55:3597-3609

32. Sigg L, Xue H, Kistler D, Schönenberger R (2000) Aquat Geochem 9:313-434

33. Gustafsson JP, http://amov.ce.kth.se/english/oursoftware/Vminteq/ index.htm 